\title{
New Site Classification System of Korea and 2016 Gyeongju Earthquakes
}

\author{
Hyung-Ik Cho ${ }^{1}$, Han-Saem Kim ${ }^{1}$, Chang-Guk Sun ${ }^{1}$, Dong-Soo Kim ${ }^{2}$ \\ ${ }^{1}$ Earthquake Research Center, Korea Institute of Geoscience and Mineral Resources \\ 124 Gwahak-ro, Yuseong-gu, Daejeon, Republic of Korea \\ hicho@kigam.re.kr; adoogen@kigam.re.kr; pungsun@kigam.re.kr \\ ${ }^{2}$ Department of Civil and Environmental Engineering, Korea Advanced Institute of Science and Technology \\ 291 Daehak-ro, Yuseong-gu, Daejeon, Republic of Korea \\ dongsookim@kaist.ac.kr
}

\section{Extended Abstract}

Korea is part of a region of low to moderate seismicity located inside the Eurasian plate with bedrock located at depths less than $30 \mathrm{~m}$, generally. However, the spectral acceleration obtained from site response analyses based on the geologic conditions of inland areas of the Korean peninsula are significantly different from the current Korean seismic code. Recently, suitable site classification scheme and design response spectra (DRS) based on local site conditions in the Korean peninsula were developed and proposed to produce reliable estimates of earthquake ground motion [1]. The new site classification system adopted bedrock depth $(\mathrm{H})$ and average $\mathrm{V}_{\mathrm{S}}$ of soil above the bedrock $\left(\mathrm{V}_{\mathrm{S} \text {,Soil }}\right.$ ) as parameters to classify the sites into sub-categories because these two factors mostly affect site amplification, especially for shallow bedrock region. The $20 \mathrm{~m}$ of depth to bedrock are selected as the initial parameter for site classification based on the trend of site coefficients obtained from the site-specific response analyses. The sites having less than $20 \mathrm{~m}$ of depth to bedrock are sub-divided into two site classes using $260 \mathrm{~m} / \mathrm{s}$ of $\mathrm{V}_{\mathrm{S} \text {,Soil }}$ while the sites having greater than $20 \mathrm{~m}$ of depth to bedrock are sub-divided into two site classes at $\mathrm{V}_{\mathrm{S} \text {,Soil }}$ equal to $180 \mathrm{~m} / \mathrm{s}$.

On September 12, 2016, Korea experienced the biggest-ever earthquake since 1978, when government started monitoring seismic activity. A series of earthquakes having maximum $\mathrm{M}_{\mathrm{L}} 5.8$ have been occurred in south-eastern Korean peninsular, Gyeongju, continuously [2]. These earthquakes have shown that Korea is no longer safe against earthquakes. The provincial government of North Gyeongsang announced that property damage from strong earthquakes and hundreds of aftershocks in Gyeongju amounts to 23 billion won (\$20.8 million) including some 4,900 shattered rooftops and cracked walls and 32 human injuries [3]. Despite these damages, the Gyeongju earthquakes made a meaningful record in the earthquake related research in Korea. Korea has been using oversea earthquake records for the development of ground motion for seismic design due to a lack of strong recorded ground motions. However, the Gyeongju earthquakes offers a great opportunity to estimate design ground motion in Korea. This can lead to better development of DRS considering real Korean geotechnical condition and earthquake amplification characteristics.

In this study, newly proposed site coefficients and corresponding-DRS [1] were verified using three-main Gyeongju earthquakes, which are greater than $\mathrm{M}_{\mathrm{L}} 4.5$ among a series of earthquakes. Firstly, the proposed DRS curves were compared with seismic responses of Gyeongju earthquakes. The proposed DRS curves showed better covering the seismic response of the Gyeongju earthquakes than those in current seismic code. Secondly, short- and long-period site coefficients $\left(F_{a}, F_{v}\right)$ from Gyeongju earthquake records were compared with the proposed site coefficients. If the distance between each pair of recording stations at soil and rock sites are less than $30 \mathrm{~km}$, it is possible to estimate site amplification characteristics by obtaining the site coefficients for an identical earthquake event. The proposed site coefficients showed similar trend $\left(\mathrm{F}_{\mathrm{a}}>\mathrm{F}_{\mathrm{v}}\right)$ with the site coefficients from the Gyeongju earthquake motions, while the site coefficients from the current seismic code showed opposite trend $\left(F_{v}>F_{a}\right)$. To sum up, the proposed site classification system and DRS reasonably represented the site amplification characteristic of shallow bedrock condition in Korea and, thus, it is possible to conclude that the newly proposed seismic provisions are more reliable and superior to those defined in the current seismic code. 


\section{References}

[1] S. Manandhar, H. I. Cho and D. S. Kim, "Site classification system and site coefficients for shallow bedrock sites in Korea," J. Earthq. Eng., 2017.

[2] K. H. Kim, T. S. Kang, J. Rhie, Y. Kim, Y. Park, S. Y. Kang \& C. Kong, "The 12 September 2016 Gyeongju earthquakes: 2. Temporary seismic network for monitoring aftershocks," Geosciences J., vol. 20, no. 6, pp. 753-757, 2016.

[3] E. K. Choi, Y. H. Kim and E. Chung, "Gyeongju quakes cost 23 billion won in damages," Korea Joongang Daily, 2016 . 